\title{
The effect of feeding frequency and meal size on amounts of total and parotid saliva secreted by sheep
}

\author{
BY RICHARD R. CARTER ${ }^{1 *}$, O. BRIAN ALLEN ${ }^{2}$ AND W. LARRY GROVUM ${ }^{1}$ \\ Departments of ${ }^{1}$ Biomedical Sciences and ${ }^{2}$ Mathematics and Statistics, University of Guelph, \\ Guelph, Ontario NIG 2Wl, Canada
}

(Received 8 September 1989 - Accepted 10 October 1989)

\begin{abstract}
Total and unilateral parotid saliva production during eating were measured in response to offering sheep a fixed amount of lucerne (Medicago sativa) hay as one, two, four or eight meals. Total saliva measurements were obtained using sham-fed oesophageal-fistulated sheep. Unilateral parotid saliva was collected from sheep fitted with reversible re-entrant cannulas. Dry matter intakes and eating times were measured for each meal but were not constrained to particular values. Total and unilateral parotid saliva production during eating increased linearly with the $\log$ of the number of meals $(P=0.0001)$. The amounts corresponding to one, two, four and eight meals of lucerne hay were $1553,1737,1851$ and $2087 \mathrm{ml}$ during total collections and 209, 248, 307 and $352 \mathrm{ml}$ during unilateral parotid collections. The time-period spent eating and the amount of food consumed both increased as meal number increased. Total saliva collections when lucerne hay was sham-fed as one, two, four or eight meals were associated with eating times of $56.9,57.4,70.8$ and $86.0 \mathrm{~min}$ and intakes of $562,622,629$ and $638 \mathrm{~g}$ dry matter respectively. For unilateral parotid collections, eating times and dry matter intakes were $64 \cdot 2,71 \cdot 3,78 \cdot 0$, $82 \cdot 1 \mathrm{~min}$ and $515,579,614$ and $627 \mathrm{~g}$ for one, two, four and eight meals of lucerne hay respectively. The saliva production response appeared to be determined through the effects of the time-period spent eating and amounts consumed, but other undetermined effects of feeding frequency contributed to the response. The importance of meal duration on total saliva production was assessed by sham-feeding of $800 \mathrm{~g}$ lucerne as stem, leaf, hay, chopped hay or ground and pelleted hay. Increasing meal duration by feeding with stems resulted in the production of $1808 \mathrm{ml}$ saliva, whereas the rapid consumption of pellets resulted in only $\mathbf{4 4 2} \mathrm{ml}$ being produced.
\end{abstract}

Feeding frequency: Saliva: Sheep

Ruminants produce large volumes of saliva, with daily amounts ranging from 6 to 16 litres in sheep (Kay, 1960) and 98 to 190 litres in cattle (Bailey, 1961). The parotid glands contribute $40-50 \%$ of the total saliva production (Kay, 1960). Saliva is required for mastication, swallowing, fermentation in the reticulo-rumen and the onward passage of digesta. Parotid secretion rates are high at the onset of eating but decline during the course of the meal while eating continues (Carr \& Titchen, 1978). This pattern is repeated with successive meals. Hence, if food were provided as frequent meals, the repeated stimulus to parotid secretion may result in more saliva for a given intake than if food were provided as one meal. Experiments were therefore conducted to measure total saliva and unilateral parotid secretion in response to presenting a given amount of food as one or more meals. The results clearly showed that giving a set amount of food as two, four or eight meals compared with one meal increased the volume of total and unilateral parotid saliva production during eating. The response was largely determined through effects on the timeperiod spent eating and the amount consumed, although there appeared to be other effects of feeding frequency that contributed to the saliva production response.

* Present address: Bayer Australia Ltd, PO Box 159, Botany 2019, NSW, Australia. 


\section{EXPERIMENT AL}

Sheep and surgery

Five mature $(75-80 \mathrm{~kg})$ cross-bred Suffolk wethers were used in these studies. The sheep had both oesophageal fistulas (Chapman \& Grovum, 1984) and rumen fistulas (Grovum, 1988). The sheep were prepared with reversible re-entrant unilateral parotid duct cannulas (Carter \& Grovum, 1988) for parotid saliva collection in Expt 3. The aseptic precautions applied in this procedure included clipping the wool from the cheek, washing the area with soap and water, applying an iodine $(50 \mathrm{~g} / \mathrm{l})$ solution and spraying the sites where tubing passed through the cheek with a preparation containing furoxone (Topazone; Austin Joliette, Quebec). It was assumed that there was no effect of this surgery on feeding behaviour and salivary flow. The oesophageal fistulas had been in place for at least 2 years. The sheep were in good condition, ate avidly and appeared to be in no pain during the experiments. However, loss of swallowed food through the oesophageal fistula would have greatly reduced stimuli to the thoracic oesophagus and cranial reticulo-rumen, all of which may well have reflexly affected salivary flow. Unilateral parotid saliva collection may also have slowed down the rate of insalivation of chewed food and prolonged chewing time. Unilateral parotid saliva collection may have encouraged the sheep to chew on the contralateral side of the mouth, reducing ipsilateral stimulation.

\section{Housing and food}

The sheep were held in metabolism crates in a temperature-controlled room with $24 \mathrm{~h}$ lighting. Fresh water was available at all times other than during experimental meals. Lucerne (Medicago sativa) hay was available ad lib. except during experiments and was found on analysis to contain $(\mathrm{g} / \mathrm{kg}): 890$ dry matter $(\mathrm{DM}), 236$ crude protein (nitrogen $\times 6 \cdot 25$ ), 19 fat, 65 ash, 412 acid-detergent fibre.

\section{Expt 1}

Oesophageal-fistulated sheep were sham-fed to determine the total saliva production in response to a given amount of hay offered as meals which differed in size and hence number (feeding frequency). The sheep were adapted to metabolism crates and hay for $14 \mathrm{~d}$ before the start of the experiment. The design was a randomized complete block with four replications, each consisting of four $1 \mathrm{~d}$ periods. On a given day, one treatment from the following four was imposed on all five sheep: (1) one meal of $800 \mathrm{~g}$, (2) two meals of $400 \mathrm{~g}$ each, (3) four meals of $200 \mathrm{~g}$ each, (4) eight meals of $100 \mathrm{~g}$ each. In order to keep the amount of food offered constant, meal size was altered with frequency. Hence, feeding frequency and meal size were varied together, but for simplicity the treatment will be referred to as feeding frequency. All sheep received the same treatment on any given day due to the observation that parotid secretion was stimulated in sheep when they observed other sheep being fed or recognized events associated with feeding (Denton, 1957). The disadvantage of giving all sheep the same treatment on a given day was overcome by replicating the experiment four times and randomizing the order of treatments within each replicate.

Sheep had ad lib. access to hay overnight and were offered fresh hay from 08.00 to 09.00 hours. They were then fasted until the first sham-fed meal. Meal times were arranged such that the mean deprivation period was $6.5 \mathrm{~h}$ for each treatment (i.e. one meal of $800 \mathrm{~g}$ was given at 15.30 hours; two meals of $400 \mathrm{~g}$ were given at 14.30 and 16.30 hours; four meals of $200 \mathrm{~g}$ were given at $12.00,14.20,16.40,19.00$ hours; eight meals of $100 \mathrm{~g}$ were given at $12.00,13.00,14.00,15.00,16.00,17.00,18.00$ and 19.00 hours). Drinking water was removed during sham-fed meals and returned at their completion. Immediately before 
sham-feeding, the oesophageal cannulas were removed and a plastic bag was suspended from the neck of each sheep in order that ingesta recovered from the fistulas could be collected. The criteria used for declaring the end of a meal were any of the following: (a) 1.5 min with no eating, (b) food tray almost empty with the sheep nuzzling but not eating the hay, (c) repeated movement of the head in and out of the feeder without eating. At the completion of the meal, the collection bags were removed and the oesophageal cannulas replaced. Artificial saliva (McDougall, 1948) was prepared daily to replace that lost from oesophageal collections. The volume $(\mathrm{ml})$ was calculated as 1.2 times the difference between the daily oesophageal collection ( $\mathrm{g}$ ) and the total amount of food consumed ( $\mathrm{g}$ ) and was added to the rumen through the rumen cannulas after the last meal each day. The ingesta from each meal was well mixed by hand and a subsample was taken for drying in a forced air draught oven. The percentage of food recovered as collected ingesta was estimated as the difference between the weight of dry food ingested (DM $890 \mathrm{~g} / \mathrm{kg}$ ) and that recovered after a correction had been made for the DM content of the added saliva $(12 \mathrm{~g} / \mathrm{kg}$; McDougall, 1948). Total salivary water production (saliva) per meal was then calculated from the weight of food consumed, its recovery, and the weight of ingesta recovered as follows:

wet matter consumed $(\mathrm{g})=a$,

DM consumed $(\mathrm{g}):(a \times \mathrm{DM}$ of food $(\%)) / 100=b$,

water consumption (from food, $\mathrm{g}$ ): $a-b=c$,

wet ingesta collected $(\mathrm{g})=d$,

collected wet ingesta DM $(\%)=e$ (determined from ingesta subsample),

collected wet ingesta $\mathrm{DM}(\mathrm{g}):(d \times e) / 100=f$,

collected water $(\mathrm{g}): d-f=g$,

apparent saliva water $(\mathrm{g}): g-c=h$,

saliva DM $(\mathrm{g}):(h \times 1 \cdot 2 \%) / 100=i$,

collected food DM $(\mathrm{g}): f-i=j$,

fistula ingesta recovery: $j / b=k$,

adjusted total saliva $(\mathrm{g}): h / k=l$.

It was assumed that the water content of the unrecovered ingesta was the same as that of the recovered ingesta.

\section{Expt 2}

The aim of this experiment was to determine the total amount of saliva secreted in response to sham-feeding $800 \mathrm{~g}$ meals that differed markedly in form, texture and density. This was done to create a large variation in meal duration for a given intake. The objective was to assess the importance of the time-period spent eating on the values for total saliva secretion observed in Expt 1 . The design was a $5 \times 5$ Latin square with treatments being $800 \mathrm{~g}$ meals of the following forms or parts of lucerne hay as shown in Plate 1 : (1) hay, (2) chopped hay, (3) coarse stem material, (4) leaf fraction, (5) ground and pelleted hay. The treatments were assigned to five sheep for $1 \mathrm{~d}$ periods. The sheep had ad lib. access to hay overnight, were offered fresh hay from 08.00 to 09.00 hours and were then fasted for $6.5 \mathrm{~h}$ before shamfeeding commenced at 15.30 hours. Fresh drinking water was available at all times other than during the sham-fed meal. Ingesta recovered from the oesophageal fistulas were collected to calculate total saliva production.

\section{Expt 3}

The aim of this experiment was to determine whether parotid secretion in normally fed sheep was affected in the same way by feeding frequency and meal size as total saliva secretion in sham-fed sheep. Unilateral parotid saliva was collected because total-saliva 
could not be collected during normal feeding. Three of the sheep used in Expt 2 were prepared with reversible re-entrant unilateral parotid duct cannulas. This technique allowed parotid saliva to enter the animal's mouth other than during periods of saliva collection when the flow was diverted to a measuring cylinder. A randomized complete block experiment, similar to that described in Expt 1, was replicated three times with the food being lucerne hay. There was a tendency for an increase in hay intake with increasing feeding frequency. Consequently, a fourth replicate was conducted with the leaf fraction of the hay to encourage higher intakes when one or two meals were offered. The trend persisted and another replicate was conducted with $400 \mathrm{~g}$ of the leaf fraction in a second attempt to equalize total intakes across the treatments. The pattern of secretory responses was not different for the different forms or amounts given, so the leaf replicates were pooled with the hay replicates. The end of a meal was assessed by the time-period spent idling and was set at $3 \mathrm{~min}$ for $800 \mathrm{~g}$ meals, $2 \mathrm{~min}$ for $400 \mathrm{~g}$ meals, $1.5 \mathrm{~min}$ for $200 \mathrm{~g}$ meals and $1 \mathrm{~min}$ for $100 \mathrm{~g}$ meals.

\section{Statistical analysis}

The measured responses in Expts 1, 2 and 3 were saliva production (saliva), DM intake (DMI) and total time-period spent eating (time). The individual observations for each sheep were averaged for each treatment in a replicate. Since there were four replicates in Expt 1, each feeding frequency was associated with four replication means. Similarly, the five replicates in Expt 3 meant that each feeding frequency was represented by five replication means. The within-frequency regression effects were developed by analysing these replication means, and the slopes for the different frequencies were compared. Expts 1 and 3 were analysed as randomized complete blocks with each response being regressed against the common logarithm $m_{10}$ of feeding frequency. Expt 2 was analysed as a Latin square. Analyses of variance were applied to the values and means were compared using the Newman-Keuls test.

Although DMI and eating time were clearly involved in determining the amount of saliva produced during meals, these variables were not controlled in the experiments. To understand better the mechanisms causing the salivary response, a model is needed to relate the saliva response to DMI, eating time and feeding frequency.

The following model, expressed as equation 1, was found to provide a good fit to the data:

$$
y_{i j}=a+b_{j}+c_{i} \mathrm{DMI}_{i j}+d_{i} \text { time }_{i j}+e_{i j}
$$

where $y_{i j}, \mathrm{DMI}_{i j}$ and time ${ }_{i j}$ are saliva, DMI and eating time respectively for the $j$ th replicate of the $i$ th treatment; $c_{i}$ is the slope of the relationship between saliva and DMI for treatment (feeding frequency) $i ; d_{i}$ is the slope of the relationship between saliva and time for treatment (feeding frequency) $i ; b_{j}$ represents differences among the replicates and $e_{i j}$ represents the residual error. It must be understood that the slopes $c$ and $d$ represent the change within a feeding frequency and not changes in the mean saliva production across the feeding frequency treatments. In fact, $c_{1}$ is the increase in saliva production for a feeding frequency of one meal of $800 \mathrm{~g}$ when DMI increases by $1 \mathrm{~g}$. Similarly, $c_{2}$ represents the increase in saliva production when DMI increases by $1 \mathrm{~g}$ for two meals of $400 \mathrm{~g}$. If feeding frequency per se affected saliva production, then it would be expected that $c_{1}, c_{2}, c_{3}$ and $c_{4}$ would not all be equal. For any replicate, keeping time fixed, the relationship between $y$ and DMI can be viewed as a series of regressions with a different slope for each treatment (feeding frequency). The same discussion applies to $d$, the slope of the relationship between saliva and the time-period spent eating, holding DMI constant. Hence, effects due to frequency of feeding per se appear as different values for $c_{1}-c_{4}$ and $d_{1}-d_{4}$.

Graphical analyses of the residuals (Snedecor \& Cochran, 1980a) indicated that this model fitted the values well. The model was simplified by removing DMI or time when it did not affect the goodness of fit. 
The use of simple ratios, such as saliva: time, saliva:DMI or saliva:DMI: time, was not appropriate here since the relationship between the numerator and the denominator variables did not have a zero intercept (Snedecor \& Cochran, 1980 b). For example, plots of saliva $v$. DMI or time did not pass through the origin but rather resulted in a positive intercept on the 'saliva' axis. Curvilinear responses may explain such a result, but only linear relationships were justified for the limited values in the present study. An explanation for a positive intercept value relating saliva to DMI is that parotid flow in adult ruminants is continuous even when the animal is not eating or ruminating (Kay, 1958).

\section{RESULTS}

\section{Expt 1}

There was a $34.3 \%$ increase $(P=0.0001)$ in total saliva production when sheep were fed eight times compared with once. Total saliva production increased linearly with the log of feeding frequency over the range from one to eight meals (Table 1). However, both DMI and time also increased linearly with the $\log$ of feeding frequency (Table 1). The mean recovery of ingested hay from the oesophageal fistulas was 89.5 (SE 0.79 ) \% ( $n 300$ meals).

The model defined in equation 1 was also fitted to the values. DMI was not significant and was removed from the model. Fig. 1 shows the regressions of saliva $v$. total eating time for each of the four feeding frequencies (with the mean total time-period spent eating for each of the feeding frequencies shown). The ordinate associated with each time is the mean total saliva production for each frequency. Saliva production was a function of total timeperiod spent eating but the rate of production per unit time is different for each feeding frequency. The slopes for one and two meals were significantly negative whereas the slopes for four and eight meals were not significantly different from zero. The regression coefficients are shown in Table 1 and comparison of all pairs indicated that each slope is different from the others.

\section{Expt 2}

Offering sheep lucerne as long hay, chopped hay, ground and pelleted hay or the stem or leaf fraction of the hay did not affect DMI but the time-period spent sham-feeding was significantly affected (Table 2). The decrease in the time-period spent consuming leaf and pellets was associated with a significantly lower total saliva production compared with the other treatments. Clearly, decreasing the duration of the meal with intake being similar led to lower saliva production.

The model that most adequately described the values for total saliva production resulted in separate regression equations $(2-6)$ for each food form as follows:

stem fraction

chopped hay

hay

leaf fraction

ground and pelleted hay

$$
\begin{aligned}
& \text { saliva }=23 \cdot 9+8 \cdot 31 \text { (time) }+2 \cdot 13(\mathrm{DMI}), \\
& \text { saliva }=23 \cdot 9+8 \cdot 31(\text { time })+2 \cdot 12(\mathrm{DMI}), \\
& \text { saliva }=23 \cdot 9+8 \cdot 31(\text { time })+1 \cdot 94(\mathrm{DMI}), \\
& \text { saliva }=23 \cdot 9+8 \cdot 31(\text { time })+1 \cdot 74(\mathrm{DMI}), \\
& \text { saliva }=23 \cdot 9+8 \cdot 31(\text { time })+0 \cdot 52(\mathrm{DMI}),
\end{aligned}
$$

where saliva is the estimated total saliva production (ml), time is the meal duration (min) and DMI is expressed in $\mathrm{g}$. The time-period spent eating had the same effect in determining the total saliva production for all food forms. The regression coefficients relating DMI to saliva are listed in Table 2. Whilst DMI was important in determining saliva production, the slope values varied for the different forms and fractions of the hay. Pelleted hay differed significantly from all other forms, whereas the leaf differed from all other treatments except hay. The stem fraction, chopped hay and long hay had slope values which were not significantly different. All the slope values for DMI were significantly different from zero ( $P=0.0001$ for equations $2,3,4,5$ respectively and $P=0.0144$ for equation 6$)$. 
Table 1. Expt 1. Effect of frequency of sham-feeding lucerne (Medicago sativa) hay ( $800 \mathrm{~g}$ was provided as one, two, four or eight separate meals) on total saliva production (saliva), dry matter intake (DMI), total time-period spent eating (time) and the slope of the regression of saliva on time-period spent eating in five sheep

\begin{tabular}{|c|c|c|c|c|c|c|}
\hline \multirow[b]{2}{*}{ Response } & \multicolumn{4}{|c|}{ Feeding frequency } & \multirow[b]{2}{*}{ SED } & \multirow{2}{*}{$\begin{array}{c}\text { Statistical } \\
\text { significance: } \\
P^{*}\end{array}$} \\
\hline & 1 & 2 & 4 & 8 & & \\
\hline Saliva $(\mathrm{m} l)$ & 1553 & 1737 & 1851 & 2087 & $31 \cdot 5$ & $0 \cdot 0001$ \\
\hline DMI $(g)$ & 562 & 622 & 629 & 638 & $28 \cdot 1$ & $0 \cdot 0228$ \\
\hline Time (min) & $56 \cdot 9$ & $57 \cdot 4$ & $70 \cdot 8$ & $86 \cdot 0$ & 6.6 & 0.0007 \\
\hline Time regression coefficient $\dagger$ & $-8 \cdot 75^{\mathrm{a}}$ & $-5 \cdot 44^{b}$ & $-2 \cdot 81^{\mathrm{c}}$ & $+0 \cdot 41^{\mathrm{d}}$ & 0.53 & $0 \cdot 0001$ \\
\hline
\end{tabular}

a,b,c,d Means in a row with different superscript letters were significantly different (protected $t$ test, $P<0.05$ ). SED, standard error of the difference between two row means (df 11) except for time regression coefficient where it is the average standard error of the six possible differences among the four slopes ( $\mathrm{df} 8$ ).

* The observed significance level of the slope relating the 'response' to the log of feeding frequency, except for time regression coefficient where it refers to an $F$ test of equality of regression coefficients relating total time-period spent eating to saliva production.

$\uparrow$ Time-period spent eating relative to total saliva production for each feeding frequency.

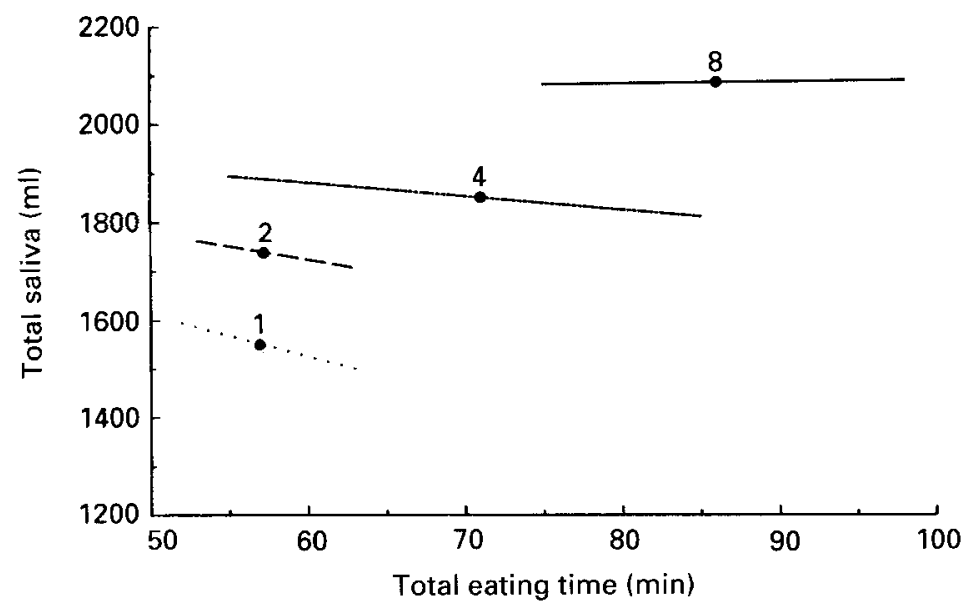

Fig. 1. Expt 1. Total saliva production in oesophageal-fistulated sheep in response to total eating time as affected by feeding frequency. A total of $800 \mathrm{~g}$ hay were sham-fed as one $(\ldots$.$) , two (---)$, four $(-\cdots-\cdots)$ or eight $(-\longrightarrow)$ meals to each of five sheep. (C), The mean values for total eating time.

\section{Expt 3}

The parotid saliva production with eight meals was $76 \cdot 1 \%$ greater than with one meal when the values were pooled as shown in Table 3 . The separate regressions of saliva, DMI and time $v$. the log of feeding frequency were linear and highly significant $(P=0.0001)$ when all five replicates were pooled (Table 3 ). The unilateral parotid saliva responses to feeding frequency with total food offerings of $800 \mathrm{~g}$ lucerne hay, $400 \mathrm{~g}$ lucerne leaf and $800 \mathrm{~g}$ lucerne leaf are presented in Fig. 2, along with the total output of saliva when $800 \mathrm{~g}$ hay was offered (Expt 1). The saliva increases in response to feeding frequency-meal size are clear for both the parotid and total collections.

The increase in food intake with increasing feeding frequency was not reduced by offering $400 \mathrm{~g}$ or $800 \mathrm{~g}$ of the leaf fraction of lucerne hay instead of $800 \mathrm{~g}$ hay. 
Table 2. Expt 2. Effect of sham-feeding different forms (long, chopped, ground and pelleted) or fractions (stem, leaf) of lucerne (Medicago sativa) on total saliva production (saliva), dry matter intake $(D M I)$, meal duration (time) and the slope of the regression of saliva on DMI in five sheep

\begin{tabular}{|c|c|c|c|c|c|c|c|}
\hline \multirow[b]{2}{*}{ Response } & \multicolumn{5}{|c|}{ Feed form } & \multirow[b]{2}{*}{ SED } & \multirow{2}{*}{$\begin{array}{r}\text { Statistical } \\
\text { significance } \\
p^{*}\end{array}$} \\
\hline & Stem & Chopped & Hay & Leaf & Pellets & & \\
\hline Saliva (ml) & $1808^{\mathrm{a}}$ & $1784^{\mathrm{a}}$ & $1766^{\mathrm{a}}$ & $1325^{b}$ & $442^{\mathrm{c}}$ & $131 \cdot 6$ & 0.0001 \\
\hline DMI (g) & 555 & 551 & 610 & 553 & 561 & $66 \cdot 6$ & 0.8410 \\
\hline Time (min) & $75 \cdot 4^{\mathrm{a}}$ & $70 \cdot 6^{\mathrm{a}}$ & $67 \cdot 2^{\mathrm{a}}$ & $41 \cdot 0^{\mathrm{b}}$ & $12 \cdot 5^{\mathrm{c}}$ & $4 \cdot 4$ & $0 \cdot 0001$ \\
\hline DMI regression coefficient $\dagger$ & $2 \cdot 13^{\mathrm{a}}$ & $2 \cdot 12^{\mathrm{a}}$ & $1.94^{\mathrm{ab}}$ & $1.74^{\mathrm{b}}$ & $0.52^{c}$ & $0 \cdot 17$ & 0.0001 \\
\hline
\end{tabular}

a,b,c Means in a row with different superscript letters were significantly different (Newman-Keuls test, $P<0.05$ )

SED, standard error of the difference between two row means (df 11) except for DMI regression coefficient where it is the average standard error of the ten possible differences among the five slopes (df 17).

* Observed significance level of $F$ test of equality of feed forms and fractions.

+ DMI relative to total saliva production for each feed form.

Table 3. Expt 3. Effect of feeding frequency on unilateral parotid saliva production (saliva), dry matter intake (DMI), time-period spent eating (time) and the slope of the regression of saliva on time and saliva on DMI in three normally fed sheep

\begin{tabular}{|c|c|c|c|c|c|c|}
\hline \multirow[b]{2}{*}{ Response and treatment } & \multicolumn{4}{|c|}{ Feeding frequency } & \multirow[b]{2}{*}{ SED } & \multirow{2}{*}{$\begin{array}{c}\text { Statistical } \\
\text { significance } \\
P^{*}\end{array}$} \\
\hline & 1 & 2 & 4 & 8 & & \\
\hline \multicolumn{7}{|l|}{ Saliva (ml) } \\
\hline Hay $(x)$ & 209 & 248 & 307 & 352 & $22 \cdot 3$ & 0.0001 \\
\hline Hay + leaf $(y)$ & 195 & 230 & 297 & 346 & $17 \cdot 5$ & 0.0001 \\
\hline Hay + leaf $(z)$ & 181 & 217 & 276 & 318 & $16 \cdot 8$ & 0.0001 \\
\hline \multicolumn{7}{|l|}{ DMI (g) } \\
\hline Hay $(x)$ & 515 & 579 & 614 & 627 & $25 \cdot 4$ & 0.0018 \\
\hline Hay + leaf $(y)$ & 479 & 533 & 585 & 626 & $32 \cdot 1$ & 0.0002 \\
\hline Hay + leaf $(z)$ & 435 & 482 & 526 & 561 & $28 \cdot 0$ & 0.0001 \\
\hline \multicolumn{7}{|l|}{ Time (min) } \\
\hline Hay $(x)$ & $64 \cdot 2$ & $71 \cdot 3$ & $78 \cdot 0$ & $82 \cdot 1$ & 49 & 0.0023 \\
\hline Hay + leaf $(y)$ & $56 \cdot 4$ & $62 \cdot 5$ & $72 \cdot 2$ & $76 \cdot 5$ & $3 \cdot 9$ & 0.0001 \\
\hline Hay + leaf $(z)$ & $49 \cdot 4$ & $55 \cdot 7$ & $63 \cdot 8$ & $68 \cdot 0$ & 32 & 0.0001 \\
\hline \multicolumn{7}{|l|}{ Time regression coefficient } \\
\hline Hay + leaf $(z)$ & $+2 \cdot 39^{\mathrm{a}}$ & $-0 \cdot 38^{b c}$ & $-0.72^{b}$ & $+1 \cdot 80^{\mathrm{ac}}$ & $1 \cdot 13$ & 0.0252 \\
\hline \multicolumn{7}{|l|}{ DMI regression coefficient $\dagger$} \\
\hline Hay + leaf $(z)$ & $0 \cdot 17^{\mathrm{a}}$ & $0.53^{\mathrm{b}}$ & $0 \cdot 64^{\mathrm{b}}$ & $0 \cdot 37^{\mathrm{ab}}$ & $0 \cdot 15$ & 0.0083 \\
\hline
\end{tabular}

a,b,c Means in a row with different superscript letters were significantly different (protected $t$ test, $P<0.05$ ). $x, 800 \mathrm{~g}$ hay fed in one, two, four or eight meals (three replicates); $y$, values from $x+$ leaf replicate $(800 \mathrm{~g}) ; z$, values from $y+$ leaf replicate $(400 \mathrm{~g})$.

SED, standard error of difference between two row means ( $x \mathrm{df} 8, y \mathrm{df} 11, z \mathrm{df} 14$ ) except for time and DMI regression coefficients where it is the average standard error of the six possible differences among the four slopes (df 7).

* Observed significance level of the slope relating the response to the log of feeding frequency, except for the time and DMI regression coefficients where it refers to an $F$ test of equality of regression coefficients.

$\dagger$ Unilateral parotid saliva production relative to time-period spent eating and dry matter intake for each feeding frequency. 


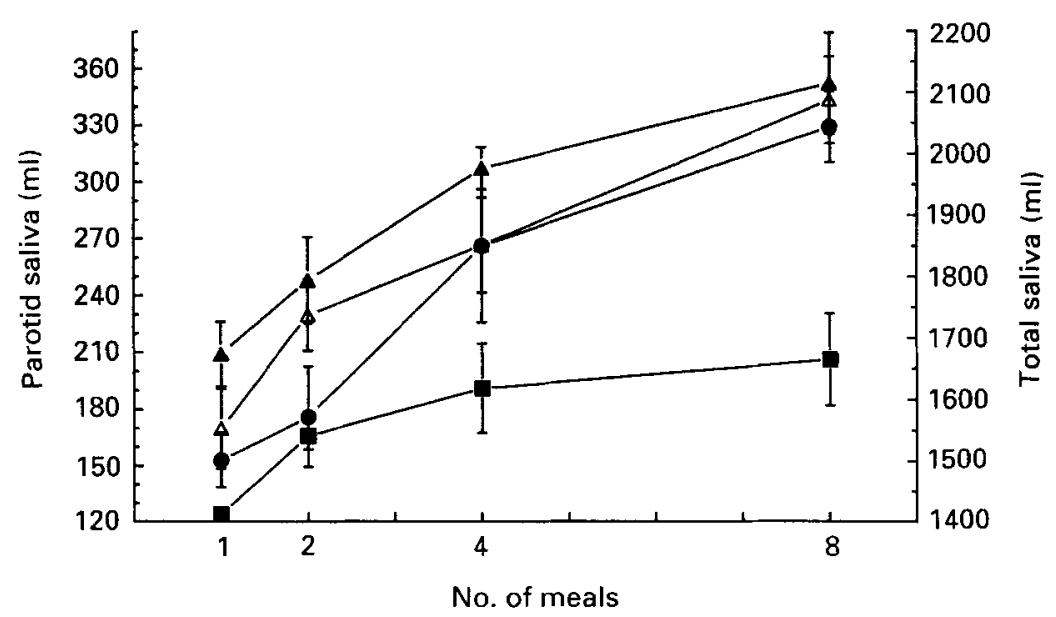

Fig. 2. Expts 1 and 3. Unilateral parotid saliva ( $n$ 3) and total saliva ( $n$ 5) produced by sheep in response to increasing feeding frequency. The total amounts of lucerne (Medicago sativa) were provided as one, two, four or eight meals: ( $\mathbf{\square}), 400 \mathrm{~g}$ lucerne leaf, parotid saliva; (O), $800 \mathrm{~g}$ lucerne leaf, parotid saliva; (A), $800 \mathrm{~g}$ lucerne hay, parotid saliva; $(\triangle), 800 \mathrm{~g}$ lucerne hay, total saliva. Values are means with their standard errors represented by vertical bars.

Fitting the model given in equation 1 showed that the effect of both DMI and the timeperiod spent eating on saliva differed among feeding frequencies. Equations 7-10 describe the saliva response for the four meal frequencies tested:

one meal

$$
\begin{aligned}
& \text { saliva }=-11.27+2.39(\text { time })+0.17(\mathrm{DMI}), \\
& \text { saliva }=-11.27-0.38(\text { time })+0.53(\mathrm{DMI}), \\
& \text { saliva }=-11.27-0.72(\text { time })+0.64(\mathrm{DMI}), \\
& \text { saliva }=-11.27+1.80(\text { time })+0.37(\mathrm{DMI}),
\end{aligned}
$$$$
\text { two meals }
$$

four meals$$
\text { eight meals }
$$

where saliva is the estimated unilateral parotid saliva production $(\mathrm{ml})$, DMI is expressed in $\mathrm{g}$ and time is the total time spent consuming the food ( $\mathrm{min})$. The regression coefficients for eating time and DMI for each feeding frequency are compared in Table 3 . Whilst there was a particular parotid salivary response to total eating time for each frequency, the slope values relating saliva production to time were not different from zero for two, four and eight meals, but for one meal it was significantly positive. The DMI slope values for frequencies two, four and eight were significantly different from zero $(P=0.0137,0.0011$ and 0.0157 respectively), indicating that increasing DMI resulted in an increase in parotid saliva production. However, the slope for one meal/d was not significant $(P=0.3076)$. Figs 3 and 4 show the plots for saliva production $v$. eating time and DMI separately. The means plotted on the graphs show first that the greatest values for total eating time and DMI were obtained with eight meals, and second that these values were associated with the greatest saliva productions. The biological significance of the different regression coefficients for the different feeding frequencies is not understood as yet. Caution is needed when extrapolating these results, because with small amounts eaten quickly the parotid saliva production would apparently be negative (Fig. 4). This is not possible but can be explained because the equations were estimated from only five data-points over a relatively limited range of values for DMI and time (see Appendix 1 and 2). Furthermore, high coefficients do not necessarily result in high saliva outputs. This is clear when the slope 


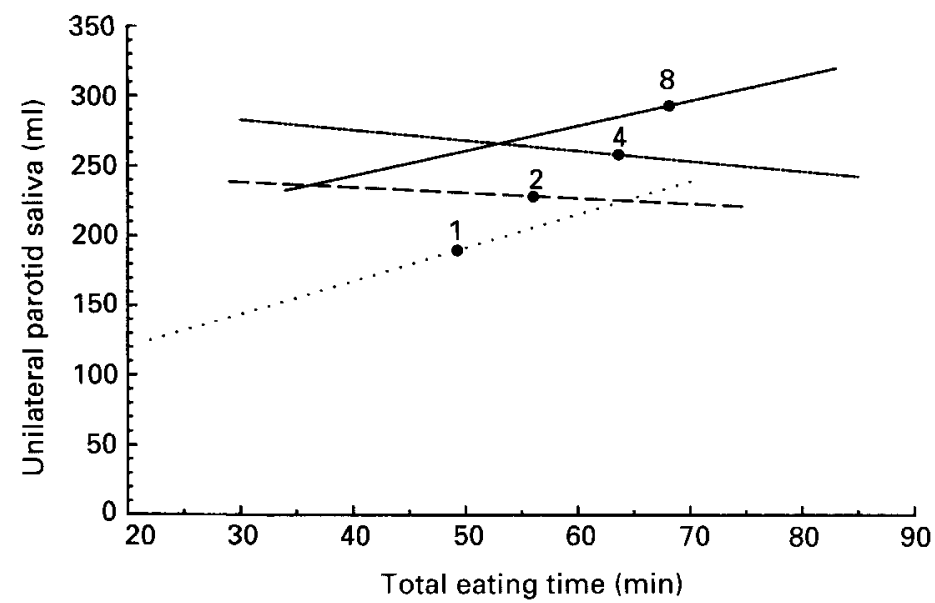

Fig. 3. Expt 3. Unilateral parotid secretion in response to total eating time as affected by feeding frequency. Total amounts of lucerne (Medicago sativa; 400 and $800 \mathrm{~g}$ ) were provided as one (...), two (---), four (-....) or eight ( $\longrightarrow$ meals to three sheep. (O), Mean values for total eating time. The plots were derived from equations 7-10 (see p. 312) using the overall average dry matter intake.

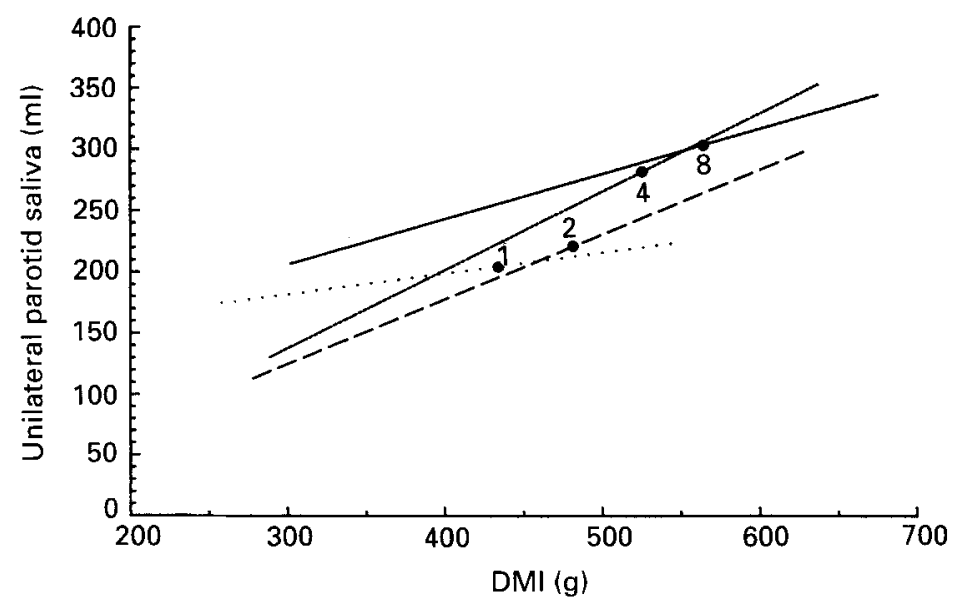

Fig. 4. Expt 3. Unilateral parotid secretion in response to total dry matter intake (DMI) as affected by feeding frequency. Total amounts of lucerne (Medicago sativa; 400 and $800 \mathrm{~g}$ ) were provided as one (...), two (...), four $(-\cdots-\cdots)$ or eight $(-)$ meals to three sheep. (O), Mean values for DMI. The plots were derived from equations 7-10 (see p. 312) using the overall average total eating time.

values and the saliva output for eight meals are compared with the values for the other feeding frequencies. Linear regression relationships were chosen as they provided the best fit for the data. However, the authors do not claim that the model is appropriate outside the observed limits of time and DMI.

\section{DISCUSSION}

The results from Expts 1 and 3 clearly show that offering a fixed amount of food as two, four or eight meals as opposed to one leads to an increase in total and unilateral parotid saliva production associated with eating. This is an aspect of feeding frequency and meal size that had not been previously investigated. The authors recognize that saliva flow 
between meals and in association with rumination is also important for rumen function. Investigation of the effects of feeding frequency on rumination and salivation associated with this behaviour were beyond the scope of the present study. While food intake and total time-period spent eating were reported as being important in determining parotid saliva output by Wilson \& Tribe (1963) and Wilson (1963) respectively, this was confounded by both factors changing together. However, when intake was held constant in Expt 2, the importance of the time-period spent eating was demonstrated by the saliva production increase as meal duration increased. Whilst the saliva response to feeding frequency appears to be mediated through the effects on the time-period spent eating and the amount consumed, these variables are highly correlated, and this makes it difficult to determine the mechanism causing the salivary response. However, the analysis presented indicates that over and above the DMI and eating time components, there were also other effects of feeding frequency contributing to the saliva output. These effects were manifested as different values for the coefficients in the DMI and time terms in the equations developed to describe saliva production. Experiments designed to constrain DMI and eating time while feeding frequency or meal size is varied widely will help to confirm whether a salivary response to feeding frequency occurs independently of these variables.

Increasing feeding frequency from one to eight meals led to a $34 \%$ increase in total saliva production in Expt 1 and an increase in total time spent eating from 57 to $86 \mathrm{~min}$. An increase in the time-period spent eating in response to feeding frequency was also observed by Gordon (1961). The linear relationship between total saliva production and the log of feeding frequency in Expt 1 suggested that each doubling of the feeding frequency would lead to a constant increase in saliva output and, thus, that there is a diminishing increment in saliva output with increasing feeding frequency. From relationships between total saliva production and total eating time shown in Fig. 1, progressively more positive coefficients were identified with increasing feeding frequency. Thus, at any given eating time, total saliva production was greatest for the highest feeding frequency. The mean total eating times also increased with feeding frequency (Fig. 1), and this was associated with increased total saliva production. The coefficients were significantly negative for one and two meals suggesting that the time-period spent eating is associated with less total saliva production. This is not reasonable, but the progressively more positive coefficients as feeding frequency increased are in accordance with the increasing total saliva outputs and, hence, the trend in regression coefficients could be meaningful. The apparent problem with the negative coefficients may be due to the limited range of total eating times within each frequency and the limited number of data points. Since the total time-period spent eating was not controlled and randomized in the present experiment, it may well be correlated with other unknown factors which cause the decline in saliva production. Explanations involving flow patterns and secretions by different glands are possible but unsatisfactory. Sham food intakes increased with the log of feeding frequency. However, DMI was removed from the final model describing saliva production as it was not significant. The lower sham intakes for lower feeding frequencies are difficult to explain but, to speculate, they may have been due to a reduced enthusiasm to eat because the animals had more time during the meals to realize that rewarding post-ingestive sensations were not forthcoming. Since sham-feeding responses may not be the same as those of normal feeding, their investigation may not be relevant to the production situation and, consequently, should not be unduly emphasized. However, increasing the number of observations over a greater range of eating times and DMI values may resolve more precisely the relationship between total saliva production and total eating time when one and two meals are offered.

Expt 2 demonstrated that the total saliva response to frequency of sham feeding in Expt 1 was related at least in part to the total time-period spent eating. Giving the pelleted 
lucerne and the leaf fraction led to short eating times and lower saliva productions compared with the other three treatments at equivalent intakes. Regression equations generated for each food type (equations 2-6) had a common positive coefficient for the time-period spent eating and, consequently, shorter meal durations would be expected to result in a lower saliva production. Giving pellets resulted in a significantly shorter meal duration than the other forms of lucerne, presumably because less time was spent on chewing pellets compared with the other forms, and because the diet was compressed. The influence of DMI on total saliva production varied depending on the food form, but DMI was found to make a significantly smaller contribution when the hay was ground and pelleted than when only the stems were given. This could be related to the observation that pellets required less chewing, which not only decreases the eating time for a given DMI but also provides less oral tactile stimulation to provoke parotid secretion (Kay, 1958). Less oral tactile stimulation could relate to both duration and extent, but information is not available to describe the relative extents of tactile stimulation with different feed forms. Parotid saliva flow in man increases not only with increases in the frequency and force of chewing, but also with the number of teeth involved (Kjeilen et al. 1987). These variables of chewing had their greatest influence when increased from a low level of activity. Such observations may apply in sheep.

A biological implication can be derived from the model describing saliva production in Expt 2. The positive intercept (23.9) and the common regression coefficient for time or meal duration $(8.31)$ dictates that short meals will be associated with higher average saliva secretion rates than longer meals. This mathematical requirement derived from the application of the statistical model in equation 1 can be supported biologically. Parotid saliva, known to constitute approximately half the total saliva production (Kay, 1960), is stimulated at the onset of a meal but declines rapidly during eating (Carr \& Titchen, 1978). Thus, short meals would capture the brief peak in parotid flow and not be associated with the lower secretion rates that occur as the meal progresses. Hence, during short meals, such as when pellets were given, the stimulated parotid flow at the onset of eating would contribute a greater proportion to the total salivary output than during longer meals such as when the stems were offered. This translates into a higher rate of saliva secretion per unit time for the consumption of pellets than for stems and this is confirmed by the values in Table 2.

Unilateral parotid saliva was collected in Expt 3 to determine how the parotid secretory response to increased feeding frequency with normal feeding compared with the outputs of total saliva during sham-feeding in Expt 1. Increasing frequency led to an increase in DMI, the time-period spent eating and parotid saliva output. The increase in parotid saliva output according to Table 3 was $76 \%$ when the meal frequency was increased from one to eight. The increase was linearly related to the $\log$ of feeding frequency, as was found for the total saliva response. The respective increases in unilateral parotid and total saliva when the meal frequency was increased from one to eight were 76 and $34 \%$, but this represented $137 \mathrm{ml}$ compared with $533 \mathrm{ml}$ of saliva respectively.

It is clear that offering food as eight meals resulted in the greatest parotid and total production of saliva because this frequency also resulted in the highest mean values for DMI and total eating time, as shown in Tables 1 and 3. There is evidence from the findings that there were frequency effects per se on saliva production due to significantly different regression coefficients for DMI and time for the different frequencies (Tables 1 and 3), but it is at present difficult to draw conclusions about their possible biological significance as the trends in coefficients were not consistent.

The increase in DMI with feeding frequency in Expt 3 (normal feeding) is worth noting. The response could not be eliminated by offering 800 or $400 \mathrm{~g}$ lucerne leaf rather than hay. 
This intake response was unlikely to have been due to the criterion used to decide the end of a meal because the time allowance for meal completion was greater at the lower than at the higher frequencies. Reviews on the effects of feeding frequency cite studies in which intake has increased with increased frequency of feeding (Burt \& Dunton, 1967; Gibson, 1984). In most of these experiments, food was offered at fixed levels or in predetermined amounts (Gibson, 1984) as was done in the present study. There was no increase in ad lib. intakes of high forage diets in cattle when food was offered once or four times daily (Ruiz \& Mowat, 1987).

Due to the important role of saliva in the ruminant, perturbations in salivary flow can have profound effects on animal production. Severing the parotid ducts and nerves in sheep resulted in an increase in the DM content of the rumen, decreased cellulose digestion and a marked reduction in food intake (Wilson, 1964). Saliva flow to the rumen can influence the volume: flow ratio of the contents and so affect the retention time of food in the rumen and the extent of rumen digestion. The intrarumen infusion of artificial saliva increased the rumen dilution rate and increased the amount of protein and starch passed to the duodenum (Harrison et al. 1975). Increases in rumen dilution rate were also reported when the salts of artificial saliva were incorporated into a pelleted diet given to sheep (Thomson et al. 1978). Increases in salivary flow in sheep and cattle have been produced following consumption of slaframine-contaminated red clover (Trifolium pratense) or intramuscular injections of slaframine, a parasympathomimetic secretogogue isolated from Rhizoctonia leguminicola, and this was associated with an increased rumen dilution rate (Froetschel et al. 1984, 1987). Increased fluid passage from the rumen may facilitate particulate passage (Owens \& Goetsch, 1986). Consequently, it could be speculated that manipulating feeding regimens or using chemical stimulants to increase saliva flow may increase food intake. During eating there is also an increase in fluid outflow from the rumen (Warner \& Stacy, 1968; Teeter \& Owens, 1983). The contribution of the increased salivary flow during eating to this increased outflow rate, and the subsequent effects on rumen function and intake requires further experimentation.

Skilled technical assistance was provided by Warren Bignell. Funding was provided by the National Sciences and Engineering Research Council of Canada (Grant A2377) and by the Ontario Ministry of Agriculture and Food.

\section{REFERENCES}

Bailey, C. B. (1961). Saliva secretion and its relation to feeding in cattle. 3. The rate of secretion of mixed saliva in the cow during eating, with an estimate of the magnitude of the total daily secretion of mixed saliva. British Journal of Nutrition 15, 443-451.

Burt, A. W. A. \& Dunton, C. R. (1967). Effect of frequency of feeding upon food utilization by ruminants. Proceedings of the Nutrition Society 26, 181-190.

Carr, D. H. \& Titchen, D. A. (1978). Post prandial changes in parotid salivary secretion and plasma osmolality and the effects of intravenous infusions of saline solutions. Quarterly Journal of Experimental Physiology 63 $1-21$.

Carter, R. R. \& Grovum, W. L. (1988). Reversible re-entrant cannulation of the parotid duct in sheep. Canadian Journal of Animal Science 68, 305-309.

Chapman, H. W. \& Grovum, W. L, (1984). Esophageal fistulation of sheep for sham feeding studies. Canadian Journal of Animal Science 64, 106-107.

Denton, D. A. (1957). A gregarious factor in the natural conditioned salivary reflexes of sheep. Nature 16, 341-344

Froetschel, M. A., Croom, W. J., Hagler, W. M., Argenzio, R. A., Liacos, J. A. \& Broquist, H. P. (1987). Effects of slaframine on ruminant digestive function: Liquid turnover rate and fermentation patterns in sheep and cattle. Journal of Animal Science 64, 124I-1248.

Froetschel, M. A., Croom, W. J., Hagler, W. M., Broquist, H. P. \& Gaskins, R. (1984). Effects of slaframine on salivary flow and rumen function. Canadian Journal of Animal Science 64, 64-65. 
Gibson, J. P. (1984). The effects of frequency of feeding on milk production of dairy cattle: an analysis of published results. Animal Production 38, 181-189.

Gordon, J. G. (1961). The relationship between rumination and frequent feeding. Animal Behaviour 9, 16-19.

Grovum, W. L. (1988). Inserting a rumen cannula in sheep to minimize leakage. Canadian Journal of Animal Science 68, 561-563.

Harrison, D. G., Beever, D. E., Thomson, D. J. \& Osbourn, D. F. (1975). Manipulation of rumen fermentation in sheep by increasing the rate of flow of water from the rumen. Journal of Agricultural Science, Cambridge $\mathbf{8 5}$, 93-101.

Kay, R. N. B. (1958). Continuous and reflex secretion by the parotid gland in ruminants. Journal of Physiology $144,463-475$.

Kay, R. N. B. (1960). The rate of flow and composition of various salivary secretions in sheep and calves. Journal of Physiology 150, 515-537.

Kjeilen, J. C. J., Brodin, P., Aars, H. \& Berg, T. (1987). Parotid salivary flow in response to mechanical and gustatory stimulation in man. Acta Physiologica Scandinavica 131, 169-175.

McDougall, E. I. (1948). Studies on ruminant saliva. 1. The composition and output of sheep's saliva. Biochemical Journal 43, 99-109.

Owens, F. N. \& Goetsch, G. L. (1986). Digesta passage and microbial protein synthesis. In Control of Digestion and Metabolism in Ruminants, pp. 196-223 [L. P. Milligan, W. L. Grovum and A. Dobson, editors]. Engelwood Cliffs, New Jersey: Prentice Hall.

Ruiz, A. \& Mowat, D. N. (1987). Effect of feeding frequency on the utilization of high-forage diets by cattle. Canadian Journal of Animal Science 67, 1067-1074.

Snedecor, G. W. \& Cochran, W. G. (1980a). Statistical Methods, 7th ed., p. 349, Iowa: Iowa State University Press.

Snedecor, G. W. \& Cochran, W. G. (1980b). Statistical Methods, 7th ed., pp. 172-174, Iowa: Iowa State University Press.

Teeter, R. G. \& Owens, F. N. (1983). Characteristics of water soluble markers for measuring rumen liquid volume and dilution rates. Journal of Animal Science 56, 717-728.

Thomson, D. J., Beever, D. E., Latham, M. J., Sharpe, M. E. \& Terry, R. A. (1978). The effect of inclusion of mineral salts in the diet on dilution rate, the pattern of rumen fermentation and the composition of the rumen microflora. Journal of Agricultural Science, Cambridge 91, 1-7.

Warner, A. C. I. \& Stacy, B. D. (1968). The fate of water in the rumen. 2. Water balances throughout the feeding cycle in sheep. British Journal of Nutrition 22, 389-410.

Wilson, A. D. (1963). The effect of diet on the secretion of parotid saliva by sheep. II. Variations in the rate of salivary secretion. Australian Journal of Agricultural Research 14, 680689.

Wilson, A. D. (1964). Parotid saliva and rumen digestion in the sheep. British Journal of Nutrition 18, $163-172$.

Wilson, A. D. \& Tribe, D. E. (1963). The effect of diet on the secretion of parotid saliva by sheep. I. The daily secretion of saliva by caged sheep. Australian Journal of Agricultural Research 14, 670-679. 
Appendix 1. Expt 1. Effect of frequency of sham-feeding $800 \mathrm{~g}$ lucerne (Medicago sativa) hay as one, two, four or eight meals

(Values are means for five sheep)

\begin{tabular}{ccccc}
\hline $\begin{array}{c}\text { Replicate } \\
\text { no. }\end{array}$ & $\begin{array}{c}\text { Feeding } \\
\text { frequency }\end{array}$ & $\begin{array}{c}\text { Dry matter } \\
\text { intake }(\mathrm{g})\end{array}$ & $\begin{array}{c}\text { Total eating } \\
\text { time (min) }\end{array}$ & $\begin{array}{c}\text { Total saliva } \\
(\mathrm{ml})\end{array}$ \\
\hline 1 & 1 & $565 \cdot 6$ & $52 \cdot 0$ & $1554 \cdot 2$ \\
1 & 2 & $591 \cdot 8$ & $63 \cdot 0$ & $1713 \cdot 0$ \\
1 & 4 & $580 \cdot 2$ & $85 \cdot 4$ & $1747 \cdot 8$ \\
1 & 8 & $606 \cdot 6$ & $98 \cdot 0$ & $2019 \cdot 8$ \\
2 & 1 & $513 \cdot 4$ & $63 \cdot 0$ & $1447 \cdot 0$ \\
2 & 2 & $637 \cdot 8$ & $53 \cdot 0$ & $1741 \cdot 6$ \\
2 & 4 & $572 \cdot 6$ & $77 \cdot 4$ & $1817 \cdot 8$ \\
2 & 8 & $674 \cdot 2$ & $76 \cdot 2$ & $2029 \cdot 2$ \\
3 & 1 & $527 \cdot 8$ & $54 \cdot 0$ & $1474 \cdot 8$ \\
3 & 2 & $597 \cdot 6$ & $57 \cdot 4$ & $1605 \cdot 4$ \\
3 & 4 & $675 \cdot 4$ & $55 \cdot 2$ & $1760 \cdot 8$ \\
3 & 8 & $588 \cdot 4$ & $94 \cdot 4$ & $1999 \cdot 4$ \\
4 & 1 & $642 \cdot 8$ & $58 \cdot 4$ & $1737 \cdot 8$ \\
4 & 2 & $662 \cdot 0$ & $56 \cdot 4$ & $1887 \cdot 4$ \\
4 & 4 & $688 \cdot 0$ & $65 \cdot 4$ & $2078 \cdot 8$ \\
4 & 8 & $685 \cdot 0$ & $75 \cdot 4$ & $2298 \cdot 0$ \\
\hline \hline
\end{tabular}

Appendix 2. Expt 3. Effect of frequency of feeding $800 \mathrm{~g}$ lucerne (Medicago sativa) hay (replicates 1-3) and $800 \mathrm{~g}$ and $400 \mathrm{~g}$ lucerne leaf (replicates 4 and 5 respectively) as one, two, four or eight meals in normally fed sheep

(Values are means for three sheep)

\begin{tabular}{ccccc}
\hline \hline $\begin{array}{c}\text { Replicate } \\
\text { no. }\end{array}$ & $\begin{array}{c}\text { Feeding } \\
\text { frequency }\end{array}$ & $\begin{array}{c}\text { Dry matter } \\
\text { intake }(\mathrm{g})\end{array}$ & $\begin{array}{c}\text { Total eating } \\
\text { time (min) }\end{array}$ & $\begin{array}{c}\text { Single parotid } \\
\text { saliva }(\mathrm{m})\end{array}$ \\
\hline 1 & 1 & $499 \cdot 8$ & $68 \cdot 3$ & $194 \cdot 8$ \\
1 & 2 & $551 \cdot 9$ & $66 \cdot 7$ & $212 \cdot 3$ \\
1 & 4 & $612 \cdot 4$ & $73 \cdot 2$ & $290 \cdot 0$ \\
1 & 8 & $613 \cdot 1$ & $80 \cdot 7$ & $303 \cdot 6$ \\
2 & 1 & $499 \cdot 1$ & $52 \cdot 7$ & $188 \cdot 8$ \\
2 & 2 & $632 \cdot 0$ & $72 \cdot 7$ & $289 \cdot 8$ \\
2 & 4 & $637 \cdot 5$ & $81 \cdot 3$ & $328 \cdot 0$ \\
2 & 8 & $675 \cdot 5$ & $83 \cdot 2$ & $396 \cdot 5$ \\
3 & 1 & $545 \cdot 1$ & $71 \cdot 5$ & $242 \cdot 8$ \\
3 & 2 & $553 \cdot 9$ & $74 \cdot 7$ & $240 \cdot 8$ \\
3 & 4 & $592 \cdot 7$ & $85 \cdot 4$ & $302 \cdot 8$ \\
3 & 8 & $592 \cdot 6$ & $82 \cdot 6$ & $355 \cdot 7$ \\
4 & 1 & $338 \cdot 6$ & $33 \cdot 1$ & $152 \cdot 7$ \\
4 & 2 & $356 \cdot 7$ & $36 \cdot 2$ & $176 \cdot 2$ \\
4 & 4 & $456 \cdot 0$ & $49 \cdot 0$ & $266 \cdot 5$ \\
4 & 8 & $581 \cdot 4$ & $59 \cdot 4$ & $329 \cdot 0$ \\
5 & 1 & $257 \cdot 6$ & $21 \cdot 7$ & $124 \cdot 2$ \\
5 & 2 & $278 \cdot 4$ & $28 \cdot 6$ & $165 \cdot 8$ \\
5 & 4 & $289 \cdot 4$ & $30 \cdot 2$ & $191 \cdot 2$ \\
\hline
\end{tabular}



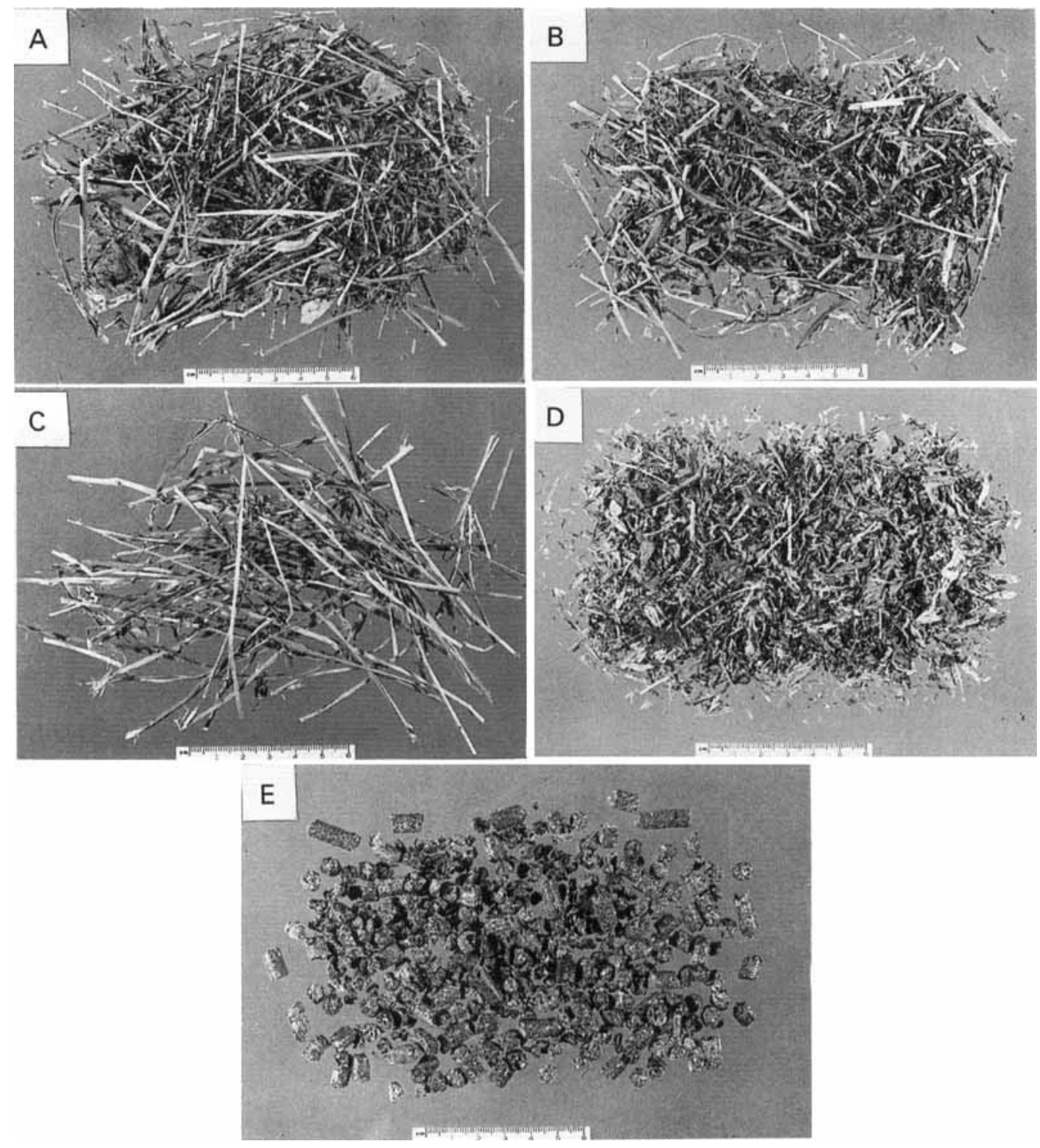

EXPLANATION OF PLATE

Plate 1. Expt 2. Forms and parts of lucerne (Medicago sativa) used. A, hay; B, chopped hay; C, stem fraction; D, leaf fraction; $\mathrm{E}$, pellets. 